\title{
Variation in the Normal Hearing Threshold Predicts Childhood IQ, Linguistic, and Behavioral Outcomes
}

\author{
DAVID WELCH AND PATRICK J.D. DAWES \\ Department of Preventive and Social Medicine [D.W.], Department of ORL-HNS [P.J.D.D.], Dunedin School of Medicine, \\ University of Otago, Dunedin 9054, New Zealand
}

\begin{abstract}
Childhood hearing level varies considerably within the range considered normal. Four classes of outcome were investigated for associations with hearing thresholds in this range: ability to identify speech in noise, neurocognitive ability, linguistic ability, and behavior. The research was conducted in a general population cohort of 711 children with mean hearing threshold of $15 \mathrm{~dB}$ HL or better. Some outcomes: speech in noise, intelligence, and certain linguistic abilities, were predicted in both boys and girls; effects were stronger in girls. In girls only, poorer hearing predicted worse behavior. These effects remained after statistical control for childhood socioeconomic status and otitis media. Variability in normal hearing, due to causes other than otitis media, is associated with the listening, language, and neurocognitive abilities of children, and the behavior of girls. We suggest that these effects may be present for three reasons, cochlear insults, neurodevelopmental factors, and psychological factors. We discuss how these may interact to produce the effects observed.
\end{abstract}

(Pediatr Res 61: 737-744, 2007)

$\mathrm{T}$ The conventional cut-off for normal-range hearing in children is $15 \mathrm{~dB}$ HL (1); which includes 97\% (711/734) of the general population sample assessed here. This includes a wide range of actual hearing abilities, and how it relates to psychosocial consequences in humans is unclear (2). Hitherto, research has concentrated on effects in people with relatively large hearing losses, with little attention paid to the effects of variability within the normal range. We investigated four areas for which we hypothesized effects of hearing level in normally hearing children.

Identification of signals in noise. A relation between puretone detection and identification of signals in noise has been demonstrated in minimally hearing-impaired children (3). Variation in normal hearing may be due to vulnerable structures involved in the cochlear active process (4). Children with poorer normal hearing may be less able to identify signals in noise due to slight deterioration in these systems.

Neurocognitive ability. Assessment of hearing threshold measures performance on a psychoacoustical task in which general neurocognitive ability might play a part, so variation

Received August 8, 2006; accepted February 6, 2007.

Correspondence: David Welch, Ph.D., Dunedin Multidisciplinary Health and Development Research Unit, Department of Preventive and Social Medicine, Dunedin School of Medicine, PO Box 913, Dunedin 9054, New Zealand; e-mail: david.welch@dmhdru.otago. ac.nz

The Dunedin Multidisciplinary Health and Development Research Unit is funded by the Health Research Council of New Zealand.

DOI: $10.1203 / p d r .0 b 013 e 31805341 \mathrm{c1}$ in threshold might be related to IQ. Furthermore, a body of research has related sensory processing, in terms of inspection time, with IQ (5-7). Thus, there may be a relation between hearing and IQ.

Linguistic ability. Children with minimal hearing impairment perform less well on tests of educational performance, particularly in areas related to language (8). Furthermore, those with poor linguistic abilities perform less well on tests of acoustic frequency and temporal resolution $(9,10)$. These findings are with stimuli requiring a high degree of processing (11), however, simple detectability may contribute to the effects shown.

Behavior. Little research has investigated behavioral concomitants of variation in hearing in children. In deaf people, there may be effects with depression and interpersonal relations (12), and some personality factors (13). High proportions of inmates in prisons have some hearing impairment (14). Behavioral differences occur between children with minimal hearing impairment and those with normal hearing, particularly in self-esteem (8). Thus, variation in normal hearing may influence child behavior.

Effects of otitis media. Hearing threshold appears to depend partly upon history of otitis media in childhood (15). Furthermore, history of otitis media is associated with poor performance in language and academic areas during childhood $(16,17)$, behavioral problems during childhood (17), and behavior and language during adolescence (18). As such, we were careful to consider the degree of otitis media in our study of the effects of hearing level on the four areas described.

\section{METHOD}

Participants were members of the Dunedin Multidisciplinary Health and Development Study, a longitudinal investigation of a birth cohort born in Dunedin, New Zealand in 1972/1973 (19). At age 3, 1037 children $(91 \%$ of eligible births; $52 \%$ male) participated in the assessment and were followed up at ages $5,7,9,11,13$, and $15 \mathrm{y}$. Cohort families represented the full range of SES and were mainly of European descent. The Otago Ethics Committee granted ethics approval for each phase of this longitudinal study. Informed consent was obtained.

Hearing measure. Hearing thresholds were assessed in quiet conditions that were consistent across listeners. A testing protocol was used wherein any threshold better than zero $\mathrm{dB}$ HL was recorded as zero. According to previous research (20), hearing disability in adults is best correlated with a pure-tone average based on the $0.5-, 1-$, and $2-\mathrm{kHz}$ thresholds, and an average across

Abbreviations: IQ, intelligence quotient; PTA, pure tone average; SES, socioeconomic status 
Table 1. Number of measures of pure tone audiometric threshold under conditions of normal middle ear status

\begin{tabular}{lrr}
\hline & \multicolumn{2}{c}{ Number of ears } \\
\cline { 2 - 3 } Number of measures & Right & Left \\
\hline Hearing not tested & 143 & 129 \\
Never A/C1 tympanogram when tested & 125 & 118 \\
1 & 143 & 129 \\
2 & 195 & 181 \\
3 & 244 & 252 \\
4 & 330 & 357 \\
Total & 1037 & 1037 \\
Total $>1$ & 769 & 790 \\
Total $>1$ in both ears & & 734 \\
\hline
\end{tabular}

ears calculated using a weighting ratio of $4: 1$ for the better hearing ear. To generate this measure, the following steps were taken:

1. Thresholds measured alongside anything other than a type A or C1 tympanogram were discarded.

2. The mean threshold was calculated for each frequency $(0.5,1$, and $2 \mathrm{kHz})$ in each ear across the ages available. If less than two, the measure was treated as missing (Table 1).

3. The pure-tone average was calculated for each ear.

4. Average hearing was calculated as four times the threshold in the better ear plus the threshold in the worse ear, all divided by five.

In this way, the overall PTA was based upon both ears, three frequencies $(0.5,1$, and $2 \mathrm{kHz})$, and the four ages $(5,7,9$, and 11) at which pure-tone audiometry was conducted. Twenty-three children with PTA $>15 \mathrm{~dB}$ HL were excluded. The remaining 711 were those who had normal hearing according to the criterion of $15 \mathrm{~dB} \mathrm{HL}$, and with at least two normal measures of middle ear function taken during childhood.

Outcome measures. Data were collected throughout childhood (Table 2).

Identification of speech signals in noise. This was measured at ages 11 and 13 using lists of 20 common, single-syllable words under conditions of no noise, 10-, and 5-dB signal-to-noise ratio. The percentage of words identified correctly was recorded.

Neurocognitive ability. IQ was measured at ages 7, 9, 11, and 13 y using the Weschler Intelligence Scale for Children (WISC) (21).

Linguistic ability. At ages 11, 13, and 15, scores on the Burt Reading Test were obtained (22). This consists of words of progressive reading difficulty, and the score reflects number of words achieved.

The Reynell Developmental Language Scale was administered at ages 3 and 5. This involves comprehension of vocal instructions, describing pictures, and observation of language used (23). At ages 7 and 9, the Illinois Test of Psycholinguistic Abilities (ITPA) was administered. This consists of 12 subtests of different aspects of linguistic ability (24). Both the Reynell and the ITPA can provide measures of linguistic expression and comprehension.

Behavior. The Rutter Behavior Questionnaire (25) was completed by both parents and teachers at ages 5, 7, 9, and $11 \mathrm{y}$. The Rutter questionnaire has three subscales: hyperactivity, neuroticism, and antisocial behavior. Examples of items are "Often running about or jumping up and down. Hardly ever still" (hyperactivity), "Often worried, worries about many things" (neuroticism), and "Frequently fights with other children" (antisocial behavior).
Behavioral problems were assessed by parents at ages 13 and 15 using the Revised Behavior Problem Checklist (RBPC) (26). This presents statements about behavior that comprise six subscales: socialized aggression (the tendency to misbehave conjointly with others), e.g. "steals in company with others"; inattention, e.g. "inattentive to what others say"; hyperactivity, e.g., "restless, unable to sit still"; conduct disorder, e.g. "fights"; anxiety, e.g. "afraid to try new things for fear of failure"; and psychotic behavior, e.g. "expresses strange, far-fetched ideas."

Self-esteem was assessed at ages 11 and 13 using the Rosenberg SelfEsteem Scale (27). The respondent answers statements that are alternately positive (e.g. "On the whole I am happy with myself") and negative (e.g. "At times I think I am no good at all").

Longitudinal aggregation of data. We generated aggregate measures to allow us to comment upon associations between hearing level and outcomes during the childhood period as a whole, not to consider changes during the life course. We did this because, as long as consistency between measures is good, aggregate measures represent underlying phenomena more accurately than do single measures. Potential issues were that, in some cases, different tests were used (language comprehension and expression: Reynell at 3 and $5 \mathrm{y}$, ITPA at 7 and $9 \mathrm{y}$ ), different raters were used (Rutter, both parents and teachers), or mean scores changed across ages. To overcome differences in variance, scores on all scales were standardized, then combined by taking the mean across ages. We then assessed each combination of raw variables with Cronbach's alpha, which provides an index of the reliability of a set of values to be combined, scores closer to one being associated with greater reliability. These were all between 0.5 and 1, apart from the speech identification tasks that had Cronbach's alpha scores between the two ages measured of 0.298 in quiet, 0.488 at $10 \mathrm{~dB}$, and 0.437 at $5 \mathrm{~dB}$. These somewhat low values indicate that ability to identify speech in noise at age 11 is not strongly related to the ability at age 13. This may suggest that ability to identify speech in noise at the two ages could show different relations with PTA, but separate analyses by age indicated that this was not the case, so combined scores are presented.

Data analysis. Linear regression models were generated relating PTA to each of the outcomes. Relationships between PTA and other variables were checked graphically to ensure that linear regression analysis was appropriate. In some cases, there were ceiling effects (speech identification in quiet) and floor effects (the six RBPC scales). Log transformations improved these, but the outcomes of results did not differ between the two approaches, so untransformed effects are reported. Residuals were also checked graphically. Since we had observed differences between the sexes for PTA, and since there are known sex differences in many of the outcomes tested, we ran models testing for interaction effects between sex and PTA. This was necessary because interactions can either produce illusory main effects or obscure simple effects present at one level of an interacting variable.

Statistical controls. Childhood SES was an average of parental SES from birth to age 15, based on occupation (28). The average SES measure was correlated with PTA $(r=-0.0192, p<0.001)$, those with poorer SES tending to have poorer hearing. Sex was also associated with hearing in that boys tended to have better PTA [mean for boys of 7.24, and for girls of $7.81 \mathrm{~dB}$ HL; $\mathrm{t}(709)=3.03, p=0.003$ ].

\section{RESULTS}

The calculation of PTA produced a positively skewed distribution (Fig. 1). After exclusion of those with PTA $>15 \mathrm{~dB}$ $\mathrm{HL}$, the distribution was continuous from 1.67 to 15.00 , with

Table 2. Ages at which measures were taken

\begin{tabular}{|c|c|c|c|c|c|c|c|c|}
\hline & \multicolumn{8}{|c|}{ Age $(y)$} \\
\hline & Birth & 3 & 5 & 7 & 9 & 11 & 13 & 15 \\
\hline Pure-tone audiometry & & & - & - & - & - & & \\
\hline Speech in noise & & & & & & - & - & \\
\hline IQ & & & & - & - & - & - & \\
\hline Reading & & & & & & - & - & - \\
\hline Receptive language & & - & • & • & • & & & \\
\hline Expressive language & & - & • & - & • & & & \\
\hline Rutter Behavior Questionnaire & & & - & - & - & - & & \\
\hline Revised Behavior Problem Checklist & & & & & & & - & - \\
\hline Self-esteem & & & & & & & - & - \\
\hline Parental SES & - & - & - & - & - & - & - & - \\
\hline
\end{tabular}




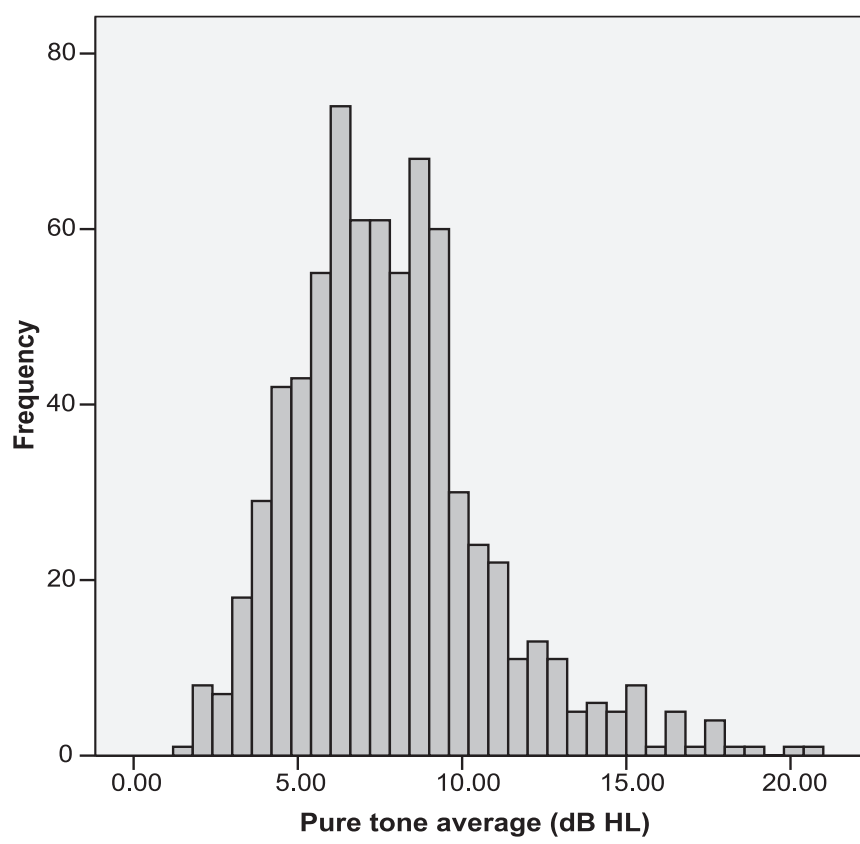

Figure 1. Frequency of audiometric pure tone averages for people with at least two measures of audiometric threshold taken under normal middle ear conditions from age 5 to $11(n=732)$. Two other people whose pure tone averages were 36 and $82 \mathrm{~dB}$ HL are not displayed.

low skewness (0.40) and kurtosis (0.02). For the purposes of comparison, the same process was carried out to generate a PTA including $0.5,1,2$, and $4 \mathrm{kHz}$. The correlation between the two measures of PTA was 0.955 , and there were no important differences in results.

Standardized regression coefficients $(\beta)$ are shown in Table 3. Those with poorer audiometric thresholds tended to perform less well at speech identification tasks, have lower IQ, read less well, use and understand language less well, be more hyperactive and neurotic, and have lower self-esteem than those with better hearing. Antisocial and problem behavior were not related to hearing threshold after controlling for sex and SES. These findings should be treated cautiously, given that sex by PTA interactions were observed in many cases.

Sex by PTA interaction effects were found to be present in all Rutter measures except Hyperactivity, all RBPC measures except Socialized Aggression, and Rosenberg Self-Esteem (all $p<0.1$ ). Regression models were developed for boys and girls separately (Tables 4 and 5).

The effects of PTA on speech-in-noise, IQ, and linguistic abilities are similar between sexes. On the other hand, girls with better hearing tended to exhibit less problem behaviors other than RBPC socialized aggression, and to have higher self-esteem, whereas no such effects occurred in boys. For illustrative purposes, boys and girls were categorized separately into tertiles based upon PTA (Table 6).

A relationship was observed between PTA and IQ. To investigate this, IQ was broken down into verbal and performance scores, which were themselves correlated at $r=0.648$. All analyses were controlled for socioeconomic status. For girls, PTA predicted verbal IQ ( $\beta=-0.113, p=0.020)$, and performance IQ $(\beta=-0.174, p<0.001)$. After controlling for performance IQ, PTA did not predict verbal IQ ( $\beta=$ $-0.012, p=0.749$ ), although it did predict performance IQ after controlling for verbal IQ ( $\beta=-0.099, p=0.016)$. For boys, PTA predicted verbal IQ $(\beta=-0.108, p=0.028)$, and marginally performance IQ $(\beta=-0.069, p=0.180)$. After controlling for performance IQ, PTA still predicted verbal IQ

Table 3. Standardized regression coefficients $(\beta)$ for childhood pure tone average and outcomes

\begin{tabular}{|c|c|c|}
\hline & $\begin{array}{l}\text { Standardized regression } \\
\text { coefficient for PTA }\end{array}$ & $\begin{array}{l}\text { Standardized regression coefficient for PTA } \\
\text { (controlling for sex and childhood SES) }\end{array}$ \\
\hline Speech detection in quiet (age 11-13) & $-0.044(p=0.267)$ & $-0.046(p=0.255)$ \\
\hline Speech detection at $5 \mathrm{~dB}$ signal-to-noise ratio (age 11-13) & $-0.128(p=0.001)$ & $-0.121(p=0.003)$ \\
\hline WISC IQ (age 7-13) & $-0.216(p<0.001)$ & $-0.127(p<0.001)$ \\
\hline Reading (age 11-15) & $-0.163(p<0.001)$ & $-0.106(p=0.003)$ \\
\hline Rutter Hyperactivity (age 5-11) & $0.103(p=0.006)$ & $0.076(p=0.034)$ \\
\hline Rutter Neuroticism (age 5-11) & $0.121(p=0.001)$ & $0.092(p=0.016)$ \\
\hline Rutter Antisocial (age 5-11) & $0.080(p=0.034)$ & $0.061(p=0.098)$ \\
\hline RBPC Socialized Aggression (age 13-15) & $0.029(p=0.445)$ & $0.013(p=0.933)$ \\
\hline RBPC Inattention (age 13-15) & $0.080(p=0.035)$ & $0.066(p=0.082)$ \\
\hline RBPC Psychotic (age 13-15) & $0.075(p=0.050)$ & $0.050(p=0.198)$ \\
\hline Rosenberg Self-Esteem (age 11-13) & $-0.152(p<0.001)$ & $-0.121(p=0.002)$ \\
\hline Sex & $-0.076(p=0.039)$ & - \\
\hline Mean Parental SES (age birth-15) & $-0.138(p<0.001)$ & - \\
\hline
\end{tabular}

$p$ Values are shown in brackets. 
Table 4. Standardized regression coefficients $(\beta)$ for childhood pure tone average and outcomes for girls

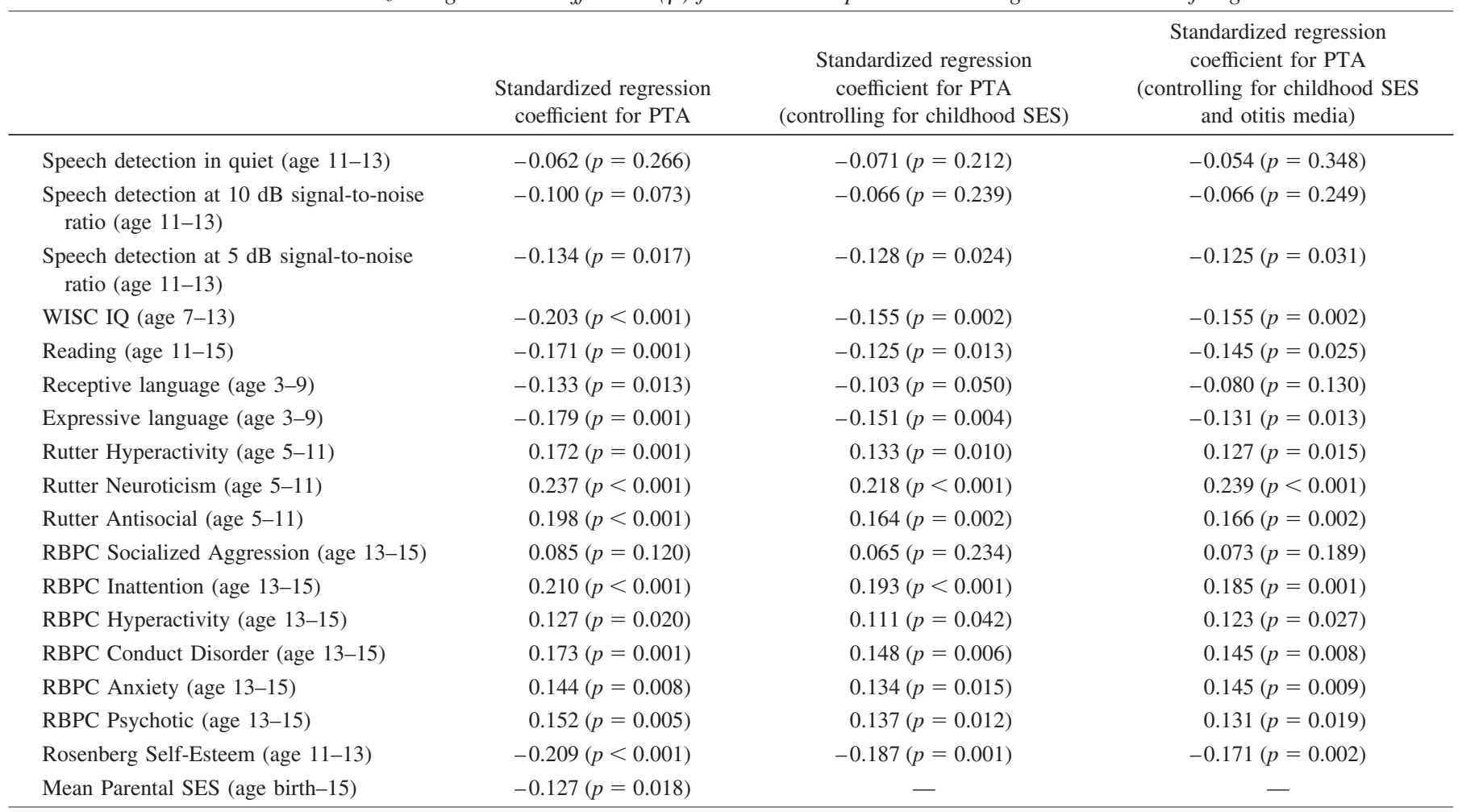

$p$ Values are shown in brackets.

Table 5. Standardized regression coefficients $(\beta)$ for childhood pure tone average and outcomes for boys

\begin{tabular}{|c|c|c|c|}
\hline & $\begin{array}{l}\text { Standardized regression } \\
\text { coefficient for PTA }\end{array}$ & $\begin{array}{c}\text { Standardized regression } \\
\text { coefficient for PTA } \\
\text { (controlling for childhood SES) }\end{array}$ & $\begin{array}{c}\text { Standardized regression } \\
\text { coefficient for PTA } \\
\text { (controlling for childhood SES } \\
\text { and otitis media) }\end{array}$ \\
\hline Speech detection in quiet (age 11-13) & $-0.024(p=0.667)$ & $-0.020(p=0.725)$ & $-0.015(p=0.807)$ \\
\hline $\begin{array}{l}\text { Speech detection at } 10 \mathrm{~dB} \\
\quad \text { signal-to-noise ratio (age 11-13) }\end{array}$ & $-0.126(p=0.022)$ & $-0.113(p=0.048)$ & $-0.100(p=0.089)$ \\
\hline $\begin{array}{l}\text { Speech detection at } 5 \mathrm{~dB} \\
\quad \text { signal-to-noise ratio (age 11-13) }\end{array}$ & $-0.118(p=0.031)$ & $-0.114(p=0.046)$ & $-0.095(p=0.106)$ \\
\hline WISC IQ (age 7-13) & $-0.218(p<0.001)$ & $-0.098(p=0.046)$ & $-0.096(p=0.057)$ \\
\hline Reading (age 11-15) & $-0.193(p<0.001)$ & $-0.089(p=0.080)$ & $-0.075(p=0.149)$ \\
\hline Receptive language (age 3-9) & $-0.116(p=0.027)$ & $-0.033(p=0.527)$ & $-0.007(p=0.890)$ \\
\hline Expressive language (age 3-9) & $-0.154(p=0.003)$ & $-0.097(p=0.068)$ & $-0.067(p=0.218)$ \\
\hline Rutter Hyperactivity (age 5-11) & $0.107(p=0.041)$ & $0.035(p=0.501)$ & $-0.002(p=0.917)$ \\
\hline Rutter Neuroticism (age 5-11) & $0.009(p=0.867)$ & $-0.024(p=0.655)$ & $-0.019(p=0.737)$ \\
\hline Rutter Antisocial (age 5-11) & $0.036(p=0.496)$ & $-0.015(p=0.778)$ & $-0.029(p=0.598)$ \\
\hline RBPC Socialized Aggression (age 13-15) & $.003(p=0.951)$ & $-0.060(p=0.261)$ & $-0.088(p=0.107)$ \\
\hline RBPC Inattention (age 13-15) & $0.0196(p=0.714)$ & $-0.033(p=0.535)$ & $-0.052(p=0.343)$ \\
\hline RBPC Hyperactivity (age 13-15) & $0.001(p=0.981)$ & $-0.055(p=0.305)$ & $-0.071(p=0.198)$ \\
\hline RBPC Conduct Disorder (age 13-15) & $-0.044(p=0.409)$ & $-0.104(p=0.051)$ & $-0.124(p=0.024)$ \\
\hline RBPC Anxiety (age 13-15) & $-0.016(p=0.770)$ & $-0.055(p=0.309)$ & $-0.059(p=0.289)$ \\
\hline RBPC Psychotic (age 13-15) & $0.025(p=0.638)$ & $-0.027(p=0.613)$ & $-0.043(p=0.438)$ \\
\hline Rosenberg Self-Esteem (age 11-13) & $-0.102(p=0.060)$ & $-0.053(p=0.338)$ & $-0.045(p=0.431)$ \\
\hline Mean Parental SES (age birth-15) & $-0.251(p<0.001)$ & - & - \\
\hline
\end{tabular}

$p$ Values are shown in brackets. 
Table 6. Tertiles of hearing ability and tertile group mean outcomes for girls and boys separately

\begin{tabular}{|c|c|c|c|c|c|}
\hline & $\begin{array}{c}\text { Tertile based } \\
\text { on hearing level }\end{array}$ & $\begin{array}{l}\text { Means for } \\
\text { tertiles within girls }\end{array}$ & SE & $\begin{array}{l}\text { Means for } \\
\text { tertiles within boys }\end{array}$ & SE \\
\hline \multirow[t]{3}{*}{ Speech detection in quiet (age 11-13) } & Best & 98.664 & 0.196 & 98.860 & 0.137 \\
\hline & Middle & 99.000 & 0.104 & 98.848 & 0.121 \\
\hline & Poorest & 98.543 & 0.131 & 98.711 & 0.150 \\
\hline \multirow{3}{*}{ Speech detection at $10 \mathrm{~dB}$ signal-to-noise ratio (age 11-13) } & Best & 91.630 & 0.338 & 91.314 & 0.296 \\
\hline & Middle & 91.131 & 0.285 & 90.610 & 0.330 \\
\hline & Poorest & 90.731 & 0.372 & 90.306 & 0.367 \\
\hline \multirow[t]{3}{*}{ Speech detection at $5 \mathrm{~dB}$ signal-to-noise ratio (age 11-13) } & Best & 80.127 & 0.497 & 79.983 & 0.455 \\
\hline & Middle & 80.369 & 0.474 & 80.960 & 0.519 \\
\hline & Poorest & 78.396 & 0.547 & 79.000 & 0.597 \\
\hline \multirow[t]{3}{*}{ WISC IQ (age 7-13) } & Best & 110.033 & 1.232 & 112.115 & 1.179 \\
\hline & Middle & 107.435 & 1.046 & 107.981 & 1.183 \\
\hline & Poorest & 103.718 & 1.283 & 105.870 & 1.297 \\
\hline \multirow[t]{3}{*}{ Reading (age 11-15) } & Best & 88.016 & 1.449 & 84.140 & 1.545 \\
\hline & Middle & 85.450 & 1.255 & 78.740 & 1.513 \\
\hline & Poorest & 81.392 & 1.507 & 76.388 & 1.772 \\
\hline \multirow[t]{3}{*}{ Receptive language (age 3-9) } & Best & 40.753 & 0.727 & 40.090 & 0.595 \\
\hline & Middle & 39.433 & 0.580 & 38.430 & 0.582 \\
\hline & Poorest & 38.511 & 0.668 & 38.539 & 0.619 \\
\hline \multirow[t]{3}{*}{ Expressive language (age 3-9) } & Best & 41.940 & 0.734 & 39.891 & 0.610 \\
\hline & Middle & 39.989 & 0.576 & 38.942 & 0.623 \\
\hline & Poorest & 39.052 & 0.633 & 37.741 & 0.661 \\
\hline \multirow[t]{3}{*}{ Rutter Hyperactivity (age 5-11) } & Best & 0.814 & 0.073 & 1.299 & 0.083 \\
\hline & Middle & 0.901 & 0.074 & 1.387 & 0.098 \\
\hline & Poorest & 1.173 & 0.083 & 1.556 & 0.107 \\
\hline \multirow[t]{3}{*}{ Rutter Neuroticism (age 5-11) } & Best & 1.499 & 0.088 & 1.666 & 0.104 \\
\hline & Middle & 1.629 & 0.081 & 1.601 & 0.078 \\
\hline & Poorest & 2.064 & 0.091 & 1.619 & 0.092 \\
\hline \multirow[t]{3}{*}{ Rutter Antisocial (age 5-11) } & Best & 0.944 & 0.080 & 1.675 & 0.116 \\
\hline & Middle & 1.187 & 0.100 & 1.430 & 0.099 \\
\hline & Poorest & 1.405 & 0.088 & 1.716 & 0.128 \\
\hline \multirow[t]{3}{*}{ RBPC Socialized Aggression (age 13-15) } & Best & 1.280 & 0.168 & 1.860 & 0.282 \\
\hline & Middle & 1.206 & 0.171 & 1.475 & 0.191 \\
\hline & Poorest & 1.715 & 0.210 & 1.617 & 0.226 \\
\hline \multirow[t]{3}{*}{ RBPC Inattention (age 13-15) } & Best & 2.624 & 0.334 & 4.665 & 0.449 \\
\hline & Middle & 2.904 & 0.280 & 4.942 & 0.456 \\
\hline & Poorest & 4.816 & 0.398 & 4.535 & 0.424 \\
\hline \multirow[t]{3}{*}{ RBPC Hyperactivity (age 13-15) } & Best & 0.587 & 0.091 & 0.907 & 0.110 \\
\hline & Middle & 0.632 & 0.085 & 0.983 & 0.115 \\
\hline & Poorest & 1.070 & 0.142 & 0.913 & 0.111 \\
\hline \multirow[t]{3}{*}{ RBPC Conduct Disorder (age 13-15) } & Best & 4.665 & 0.457 & 7.042 & 0.613 \\
\hline & Middle & 5.075 & 0.475 & 6.071 & 0.515 \\
\hline & Poorest & 6.877 & 0.528 & 5.944 & 0.577 \\
\hline \multirow[t]{3}{*}{ RBPC Anxiety (age 13-15) } & Best & 3.390 & 0.274 & 3.674 & 0.338 \\
\hline & Middle & 3.579 & 0.262 & 3.550 & 0.281 \\
\hline & Poorest & 4.430 & 0.312 & 3.252 & 0.249 \\
\hline \multirow[t]{3}{*}{ RBPC Psychotic (age 13-15) } & Best & 0.349 & 0.075 & 0.513 & 0.103 \\
\hline & Middle & 0.281 & 0.056 & 0.538 & 0.082 \\
\hline & Poorest & 0.640 & 0.090 & 0.487 & 0.080 \\
\hline \multirow[t]{3}{*}{ Rosenberg Self-Esteem (age 11-13) } & Best & 8.505 & 0.129 & 8.203 & 0.136 \\
\hline & Middle & 7.934 & 0.133 & 7.807 & 0.148 \\
\hline & Poorest & 7.610 & 0.164 & 7.905 & 0.149 \\
\hline
\end{tabular}

Outcome variable means are based on raw data. SE is the standard error of the mean within each tertile group.

marginally ( $\beta=-0.071, p=0.082)$, though not performance IQ after controlling for verbal IQ $(\beta=-0.005, p=0.911)$.

For boys, the link between PTA and IQ is via language ability leading to an apparent association between PTA and performance IQ that disappears after statistical control for the effects of verbal IQ. On the other hand, the performance IQ of girls is correlated with PTA independently of verbal IQ, whereas the relation between PTA and verbal IQ depends 
upon performance IQ. Some unknown process is occurring in girls, producing a relation between their performance IQ and hearing ability.

We considered the possibility that otitis media affected one sex more than the other, leading to our findings of sex differences. Otitis media severity measured throughout childhood (18) was used to investigate this. There was no difference between the sexes in severity of otitis media [t(709) = $0.90, p=0.369]$. When otitis media was added to the regression models described above, regression coefficients tended to be reduced slightly in both sexes (Tables 4 and 5), but its effects were largely independent of hearing. Bearing in mind that we constructed the PTA variable from audiometric thresholds taken under normal middle ear conditions, this suggests that effects of conductive loss due to current otitis media are independent of the effects we have reported.

\section{DISCUSSION}

Poorer childhood hearing threshold within the normal range predicted poorer identification of speech-in-noise, poorer IQ, poorer linguistic ability, poorer behavior, and lower selfesteem. Controlling for the effects of sex, childhood SES, and childhood otitis media tended to reduce effects slightly, but they remained in all areas. Interactions between sex and PTA occurred for the behavioral outcomes; PTA did not predict behavior in boys, but in girls, poorer PTA predicted more problem behaviors. According to Cohen's classification of effect sizes, standardized regression coefficients represent small effects at 0.1 , and moderate at 0.3 (29). Thus, overall effects tended to be small, but separate analyses of the behavioral outcomes by sex suggest that effects in girls are small to moderate, and in boys are near zero.

The causes of variability in PTA are unknown but may be classified into three areas. Insults such as noise exposure (30) and the sequelae of otitis media, possibly reducing middle ear conductivity, and/or causing sensorineural loss (31) are one class. We were careful to avoid the acute effects of otitis media in our measure of PTA, and statistical control for degree of childhood otitis media did not explain the effects observed, but this class of possibility must be considered.

A second class of causes of variability in PTA may be of genetic origin. Recessive genes for deafness may potentially influence hearing without producing clinical levels of hearing impairment (32). Genetic factors relating to the normal development of elements of the auditory system may be another. For example, it is known that people with bigger cochleae have more sensory cells (33), so they might also have greater sensitivity, or greater redundancy enabling resistance to damage. Neurodevelopmental growth factors may influence both the development of the cochlea and other functioning of the nervous system, potentially leading to the effects observed here (34).

Ability or inclination to listen selectively may be a third class of influence on PTA: the psychological. It is believed that younger children tend to have broader tuning of auditory filters than older (35), which suggests that learning takes place during maturation, and the rate of learning may vary, leading to variability in hearing threshold. Cognitive factors such as attention to test stimuli may cause variability in terms of sensory threshold, but are dependent on nonsensory factors. Similarly, personality may influence response bias, so that some children may appear to be more sensitive when they were really just more inclined to say that they could detect stimuli. More compliant children may try harder at the test than others. Linguistic development may have a feedback relationship with hearing ability in that those with better hearing may learn to speak more readily, and faster learners of language may fine-tune listening skills, and thus train the auditory cortex more quickly than others.

These three potential types of explanation: insults from noise or disease, genetic variation in neurodevelopment, and psychological characteristics may all be associated with PTA in different ways. It is impossible to state a single direction for these effects, or even to imagine that they are independent of each other. One could consider that the primary direction of influence of insults may be upon hearing, and upon other characteristics as a result of that. The primary influence of genetic variation may be considered to be a parallel influence upon hearing and upon other characteristics that depend upon neurodevelopmental conditions. The primary influence of the psychological characteristics described may be to influence hearing, rather than to be influenced by it. Nonetheless, it would oversimplify the position to suggest that these primary effects were the only effects, and probably both feedback relationships and interactions between the three would occur.

Hearing and IQ. The findings showed that IQ was predicted by PTA. Results were presented in standardized units, so for the purposes of illustration means for subgroups were calculated using actual IQ scores. Those with PTA from 1 to $5 \mathrm{~dB}$ HL had a mean IQ of 111.0, whereas those with PTA from 10 to $15 \mathrm{~dB}$ HL had a mean IQ of 103.7. This relation between sensory threshold and IQ might be an effect of poorer hearing leading to poorer language skill, which in turn led to poorer performance on IQ tests, and in boys the relation between PTA and IQ was a result of linguistic ability. On the other hand, in girls, PTA related directly to performance IQ. This is an interesting finding, but one for which we have no explanation.

Hearing and linguistic outcomes - Speech in noise. PTA predicted ability to identify speech in noise, but not in quiet. This suggests that those with poorer normal hearing performed disproportionately poorly with degraded signals. The cochlear active process is thought to account for the first 30 $\mathrm{dB}$ or so of hearing sensitivity, and to have an important role in tuning (36). Thus, small losses, which would not necessarily move a person's threshold into the levels regarded as impaired, may influence the capacity of the cochlea to resolve masked signals. Furthermore, there is a growing body of evidence suggesting that there is neural modulation of the cochlea to improve the detectability of signals in noise (37). The idea that one cause of poorer normal hearing is damage to cochlear structures that mediate this process is supported by our findings.

Reading, and language comprehension and expression. Reading ability, and language comprehension and expression were predicted by PTA even after controlling for parental SES 
(Table 3). A straightforward hypothesis is that those with better hearing would have been able to hear more speech throughout their lives, and thus had better language. A feedback process may also occur, whereby those with better linguistic ability may better engage others in speech, may give adults the confidence to use more varied constructs when talking to them.

Another possibility is that the children who became the best users of language may have trained their auditory systems to perform better. The understanding of speech depends upon an ability to detect small changes in timing, frequency, and amplitude of sound, and the task in pure tone audiometry is to detect a brief tone burst. A person who has developed an ability to understand speech very well may be expected to do well on the audiometry task as well.

Hearing and behavioral outcomes. Girls with the best hearing tended to be less hyperactive, nervous, and antisocial from ages 5 to 11, less inattentive, hyperactive, misbehaved, anxious, and psychotic in behavior from ages 13 to 15 , and tended to have higher self-esteem than girls with poorer normal hearing. The possibility that the effects observed were ultimately due to IQ rather than hearing was considered. Correlations were observed between PTA and IQ as well as between the behavioral measures and IQ, so regression models were re-run while controlling for IQ, but the effects remained, suggesting that there is an independent effect of hearing ability.

In boys, however, none of the relationships between PTA and behavioral measures were apparent. We have no strong theoretical reason to explain these sex interactions, so some caution may be appropriate in the absence of supporting research. On the other hand, the presence of these interactions across so many behavioral outcomes, and the observation that, in boys, the observed relations were in the opposite direction to those in girls (Tables 4 and 5) renders them believable. One explanation is that boys are worse behaved than girls, and that because girls' misbehavior is so low, influencing factors which are insignificant in boys are significant in girls. In partial support of this view, means for boys were significantly higher than girls on three of the scales (Rutter Hyperactivity and Antisocial, and RBPC Inattention; $p=0.05$ ). Another possibility is that boys' social interactions involve more physical activity, whereas girls' involve more quiet conversation, in which an ability to hear better than normal is an asset. More detailed research into types of social interaction, perhaps using natural experiments investigating the effects of better or worse normal hearing, would allow this to be explored.

Effect size. The effect sizes observed were small to moderate, as might be expected given the complex nature of many of the outcomes, and the consequent potential for many other variables to have impact on them. In this study, effect sizes would have been reduced due to three methodological issues. Firstly, the PTA scale used was truncated at the lower end due to threshold values below zero having been recorded as zero; were the full scale available, larger effects than those observed might be expected. Secondly, though testing conditions were constant for all cases in the study, the nonsoundproofed conditions would have added error to our measures of thresh- old. Thirdly, the pure-tone audiograms were administered only to the nearest $5 \mathrm{~dB}$, which is normally adequate, but finer measurement may provide a more accurate proxy of true hearing level. These three factors must have increased the randomness in the measure of hearing used, and this in turn would have reduced the size of the effects observed. The reasonably large sample, and the repeated, longitudinal nature of the data enabled effects to be detected anyway, but better testing under more controlled conditions would provide clearer results. The understanding and interpretation of the findings would benefit from further research using smaller groups with finer assessment techniques, and we hope that this may inspire further, more directed research using more accurate measures of hearing and concentrating on specific outcome domains.

Impact of otitis media. Our analyses did not incorporate the direct effects of otitis media, because we removed thresholds taken under abnormal middle-ear conditions before analysis. We observed a slight decrease in effect size when we controlled for the extent of childhood otitis media (Tables 4 and 5 ), but a significant proportion of variance was still explained by PTA. The remaining effects were independent of, and additional to, the well-established effects of otitis media (18).

\section{Summary}

Overall, these findings support the idea that normal variation in children's hearing levels influences their lives pervasively, particularly girls. The effects reported here are independent of otitis media, so are presumably due to neurodevelopmental factors that impact upon both hearing and the other outcome variables, and/or to direct influences of hearing level upon the outcomes. This informs researchers and health professionals of potentially important social and developmental issues for children. The breadth of the findings reported opens many avenues for further more detailed research into the impact of hearing on child behavior. Future research may also investigate whether the effects observed in childhood have any impact on adult outcomes.

Acknowledgments. We thank the Dunedin Study cohort members, their parents and friends, Unit research staff, and the study founder, Phil Silva.

\section{REFERENCES}

1. Northern JL, Downs MP 1978 Hearing in Children. Williams and Wilkins, Baltimore

2. Ruben RJ 1984 An inquiry into the minimal amount of auditory deprivation which results in a cognitive effect in man. Acta Otolaryngol Suppl 414:157-164

3. Crandell CC 1993 Speech recognition in noise by children with minimal degrees of sensorineural hearing loss. Ear Hear 14:210-216

4. Bohne BA, Harding GW 2000 Degeneration in the cochlea after noise damage: primary versus secondary events. Am J Otol 21:505-509

5. Mackintosh NJ, Bennett ES 2002 IT, IQ and perceptual speed. Pers Indiv Differ 32:685-693

6. Irwin RJ 1984 Inspection time and its relation to intelligence. Intelligence 8:47-65

7. Deary IJ, Head B, Egan V 1989 Auditory inspection time, intelligence and pitch discrimination. Intelligence 13:135-147

8. Bess FH, Dodd-Murphy J, Parker RA 1998 Children with minimal sensorineural hearing loss: prevalence, educational performance, and functional status. Ear Hear 19:339-354

9. Talcott JB, Witton C, Hebb GS, Stoodley CJ, Westwood EA, France SJ, Hansen PC, Stein JF 2002 On the relationship between dynamic visual and auditory processing and literacy skills; results from a large primary-school study. Dyslexia 8:204-225 
10. Hulslander J, Talcott J, Witton C, DeFries J, Pennington B, Wadsworth S, Willcutt E, Olson R 2004 Sensory processing, reading, IQ, and attention. J Exp Child Psychol $88: 274-295$

11. Wright BA, Bowen RW, Zecker SG 2000 Nonlinguistic perceptual deficits associated with reading and language disorders. Curr Opin Neurobiol 10:482-486

12. Leigh IW, Robins CJ, Welkowitz JW, Bond RN 1989 Toward greater understanding of depression in deaf individuals. Am Ann Deaf 134:249-254

13. Furlonger B 1998 An investigation of the career development of high school adolescents with hearing impairments in New Zealand. Am Ann Deaf 143:268-276

14. Vernon M, Greenberg SF 1999 Violence in deaf and hard-of-hearing people: a review of the literature. Aggression and Violent Behavior 4:259-272

15. Sorri M, Maki-Torkko E, Alho OP 1995 Otitis media and long-term follow-up of hearing. Acta Otolaryngol 115:193-195

16. Teele DW, Klein JO, Chase C, Menyuk P, Rosner BA 1990 Otitis media in infancy and intellectual ability, school achievement, speech, and language at age 7 years. Greater Boston Otitis Media Study Group. J Infect Dis 162:685-694

17. Silva PA, Kirkland C, Simpson A, Stewart IA, Williams SM 1982 Some developmental and behavioral problems associated with bilateral otitis media with effusion. J Learn Disabil 15:417-421

18. Bennett KE, Haggard MP, Silva PA, Stewart IA 2001 Behaviour and developmental effects of otitis media with effusion into the teens. Arch Dis Child 85:91-95

19. Silva PA, Stanton WR 1996 From child to adult: the Dunedin Multidisciplinary Health and Development Study. Oxford University Press, Auckland, New Zealand

20. Lutman ME, Brown EJ, Coles RR 1987 Self-reported disability and handicap in the population in relation to pure-tone threshold, age, sex and type of hearing loss. $\mathrm{Br} \mathrm{J}$ Audiol 21:45-58

21. Weschler D 1974 The Weschler Intelligence Scale for Children-Revised. Psychological Corporation, New York

22. Scottish Council for Research in Education 1976 The Burt Reading Test. Hodder and Stoughton, London

23. Reynell J 1969 Reynell Developmental Language Scales. National Foundation for Educational Research, London
24. Kirk SA, McCarthy JJ, Kirk WD 1968 The Illinois Test of Psycholinguistic Abilities (Revised Edition). University of Illinois Press, Urbana, IL

25. Rutter M, Tizard J, Whitmore K (eds) 1970 Education, Health, and Behaviour. Longmans Green, London

26. Quay HC, Peterson DR 1987 Manual for the Revised Behavior Problem Checklist, Miami, FL

27. Rosenberg M 1965 Society and the Adolescent Image. Princeton University Press, Princeton, NJ

28. Elley WB, Irving JC 1972 A socio-economic index for New Zealand based on levels of education and income from the 1966 census. NZ J Educ Stud 7:153-167

29. Cohen J 1992 A power primer. Psychol Bull 112:155-159

30. Niskar AS, Kieszak SM, Holmes AE, Esteban E, Rubin C, Brody DJ 2001 Estimated prevalence of noise-induced hearing threshold shifts among children 6 to 19 years of age: the Third National Health and Nutrition Examination Survey, 1988-1994, United States. Pediatrics 108:40-43

31. Blakley BW, Kim S 1998 Does chronic otitis media cause sensorineural hearing loss? J Otolaryngol 27:17-20

32. Berlin M, Legum C, Muchnik C, Hildesheimer M 1999 Subclinical audiological findings in carriers of recessive genes for deafness. J Basic Clin Physiol Pharmacol 10:201-208

33. Wright A, Davis A, Bredberg G, Ulehlova L, Spencer H 1987 Hair cell distributions in the normal human cochlea. Acta Otolaryngol Suppl 444:1-48

34. Varela-Nieto I, Morales-Garcia JA, Vigil P, Diaz-Casares A, Gorospe I, SanchezGaliano S, Canon S, Camarero G, Contreras J, Cediel R, Leon Y 2004 Trophic effects of insulin-like growth factor-I (IGF-I) in the inner ear. Hear Res 196:19-25

35. Irwin RJ, Stillman JA, Schade A 1986 The width of the auditory filter in children. J Exp Child Psychol 41:429-442

36. Collet L, Levy V, Veuillet E, Truy E, Morgon A 1993 Click-evoked otoacoustic emissions and hearing threshold in sensorineural hearing loss. Ear Hear 14:141-143

37. Giraud AL, Garnier S, Micheyl C, Lina G, Chays A, Chery-Croze S 1997 Auditory efferents involved in speech-in-noise intelligibility. Neuroreport 8:17791783 